\title{
Projected changes in climate extremes over China in the 21st century from a high resolution regional climate model (RegCM3)
}

\author{
XU JiYun ${ }^{1}$, SHI Ying ${ }^{2}$, GAO XueJie ${ }^{2 *} \&$ GIORGI Filippo ${ }^{3}$ \\ ${ }^{1}$ Zhejiang Climate Center, Hangzhou 310017, China; \\ ${ }^{2}$ National Climate Center, China Meteorological Administration, Beijing 100081, China; \\ ${ }^{3}$ The Abdus Salam International Centre for Theoretical Physics, Trieste 34100, Italy
}

Received August 31, 2012; accepted October 9, 2012; published online December 6, 2012

\begin{abstract}
Based on a consecutive simulation of the 21 st century conducted by RegCM3, changes in climate extremes over China are investigated, following abasic validation of the model performances in simulating present climate. The model is one-way nested within the global model of CCSR/NIES/FRCGC MIROC3.2_hires. A total of 150-years (1951-2100) transient simulation is carried out at $25 \mathrm{~km}$ grid spacing under the IPCC SRES A1B scenario. The indices of the extremesincludes SU (summer days), FD (frost days), GSL (growing season length) for temperature, SDII (simple daily intensity index), R10 (no. of days with precipitation $\geqslant 10$ $\mathrm{mm} / \mathrm{d}$ ), and CDD (consecutive dry days) for precipitation. Results show that the model can reproduce both the spatial distribution and the values of the present day annual mean temperature and precipitationwell, and it also shows good performances in simulating the extreme indices. Following the significant warming, the indices of SU and GSL for warm events will increase while the indices of FD for cold events will decrease over China. Heavy precipitation events as measured by SDII and R10 show an general increase over the region, except the decrease ofR10 in the Northeast and central Tibetan Plateau andless change or decrease of it along the middle and lower reaches of the Yangtze River. Decrease of drynessas measured by CDD over northern part of China while increase of it over the Tibetan Plateau, Sichuan Basin and other places in southern China are simulated by the model. This leads to the less change of the regional mean CDD in the time series in the 21 st century unlike the other indices, which show clear trend of change following the time evolution.
\end{abstract}

climate change, regional climate model, climate extremes, China

Citation: $\quad \mathrm{Xu}$ J Y, Shi Y, Gao X J, et al. Projected changes in climate extremes over China in the 21st century from a high resolution regional climate model (RegCM3). Chin Sci Bull, 2013, 58: 1443-1452, doi: 10.1007/s11434-012-5548-6

Increases in both frequency and intensity of extreme weather and climate events have been reported both globally and over different regions under the background of the global warming. Due to theircritical impactson human society, economic development and natural ecological systems as well as the environment, increasing attention has been paid to the future changes in climate extremes in the studies [1-6].

Similar to other regions in the globe, changes characterized by the increase in warm days and heavy rainfall eventsanda decrease in light precipitation events have been observed over China in the late decades [7-9]. Increasing

*Corresponding author (email: gaoxj@cma.gov.cn) research efforts have also been devoted in the projection of extreme events, either by global or regional climate models (GCMs or RCMs) [10-20]. Due to their coarse resolution, the capabilityof the GCMs is in general poorover China, while high resolution RCMs shows more advantages in simulating present climate and projecting future climate changes, especially on climate extremes [21,22]. However for the existed simulation and projection conducted by RCMs, the resolution used and the duration of the simulations is still relatively low and not long enough to cover the whole 21st century. Thus further research is needed to better address the topic. Based on a 150-years continuous climate change simulation (1951-2100) by a RCM $25-\mathrm{km}$ grid spacing $[23,24]$, we evaluate the capability of the model in 
simulating present day climate extremes, both for temperature and precipitation, then report their future changes of extremes with the focus on the middle of the 21 st century in the present study. Simulation and changes inannual mean temperature and precipitationare also provided as a background of the analysis.

\section{Model, experimental design and introduction of climate extreme indices}

The RCM simulation employed in the present study is conducted by the regional climate model of the Abdus Salam International Centre for Theoretical Physics (ICTP) RegCM version 3 (RegCM3) [25] which is developed from RegCM 2 by Giorgi et al. [26,27]. The model is one-way nested within the global model of CCSR/NIES/ FRCGCMIROC3.2_hires[28], with the emission scenario of SRES A1B [29]. Domain of RegCM3 covers China continent and the surrounding areas. Horizontal resolution of RegCM3 is $25 \mathrm{~km}$ and the vertical layer is 18 with model top at $10 \mathrm{hPa}$. The model physics includes the atmospheric radiation transfer computed using the radiation package from the NCAR community climate model CCM3 [30], planetary boundary layer computations employing the nonlocal formulation of Holtslag [31], resolvable scale precipitation of SUBEX [32], convective precipitation represented using the mass flux scheme of Grell based on FritschChappell [33,34], surface processes carried out with the biosphere-atmosphere transfer scheme (BATS1e) [35], andthe ocean flux parameterization follows Zeng et al. [36]. More detailed information about the model and simulation can be found in Gao et al. [23,24].

The period of 1980-1999 is considered as present day and 2040-2059 as the middle of the 21st century. By comparing the simulation against observation, validation of the model performance in simulating the current climate is presented with the focus on climate extreme indices. Then the spatial distributions of climate extreme changesin the mid-21st century in relative to $1980-1999$, as well as the regional mean changes for each index in the 21 st century are presented.

To validate model performance, we used the observation datasetat $0.25^{\circ} \times 0.25^{\circ}$ (latitude by longitude) resolution based on the observation from over 2400 meteorological stations over China [37]. To facilitate the analysis, the model outputs are interpolated bi-linearly to this $0.25^{\circ} \times 0.25^{\circ}$ grid cell.

Six indices with 3 (SU, FD and GSL) for temperature and the other 3 (SDII, R10 and CDD) for precipitation from Frich et al. [38] and ETCCDI (Expert Team on Climate Change Detectionand Indices, http://cccma.seos.uvic.ca/ ETCCDMI/;Peterson et al., 2001) are employed in the study as shown in Table 1.

\section{Validation of the present day climate and extreme indices simulations}

\subsection{Surface air temperature and precipitation}

To evaluate the model performance in a more strict way, distribution of the differences between simulation and observation are plotted and analyzed. The annual mean temperature and precipitation are selected in validating the simulation of the mean climatology, as shown in Figure 1 .

In the observation, the temperature in eastern Chinais largely affected by latitude, characterized by a colder north and warmer south, with the maxima located in the southern coast. In western China astrong dependence on topography can be observed. Lowest temperature less than $-10^{\circ} \mathrm{C}$ are found in northern part of the Tibetan Plateau, as well as portions of Northeast andthe mountain peaks in the Northwest (Figure 1(a)). Differences between the model simulation and observation are usually within $\pm 1^{\circ} \mathrm{C}$, except for a largercold bias up to $2-5^{\circ} \mathrm{C}$ over the Tibetan Plateau (Figure 1(b)). The bias over the Tibetan Plateau is partly introduced from the driving global model [24], in the mean time it also indicates the difficulties for climate models in simulating the climate over this regionwith complex topography. It is also noted this is a region with few or no meteorological stations available, which can lead to a large uncertainty in the gridded data derived from the station observations [37]. A warm bias of exceeding $2^{\circ} \mathrm{C}$ can be found in northern part of Northeast and Northwest China which is mostly related to the systematic warm bias of the model in high latitude during the cold seasons [39]. The spatial correlation coefficient of annual mean temperature between model simulation

Table 1 Indices of climate extremes

\begin{tabular}{ll}
\hline Indices & \multicolumn{1}{c}{ Definition } \\
\hline SU (d) & No. of summer days, days with maximum temperature $>25^{\circ} \mathrm{C}$ \\
FD (d) & No. of frost days, days with minimum temperature $<0^{\circ} \mathrm{C}$ \\
GSL (d) & Growing season length: period between when $T_{\text {day }}>5^{\circ} \mathrm{C}$ for $>5 \mathrm{~d}$ and $T_{\text {day }}<5^{\circ} \mathrm{C}$ for $>5 \mathrm{~d}$ \\
SDII (m/d) & Simple daily intensity index: annual total $/$ number of $R_{\text {day }} \geqslant 1 \mathrm{~mm} \mathrm{~d}^{-1}$ \\
R10 (d) & Number of days with precipitation $\geqslant 10 \mathrm{~mm} \mathrm{~d}$ \\
CDD (d) & Maximum number of consecutive dry days $\left(R_{\text {day }}<1 \mathrm{~mm}\right)$ \\
\hline
\end{tabular}



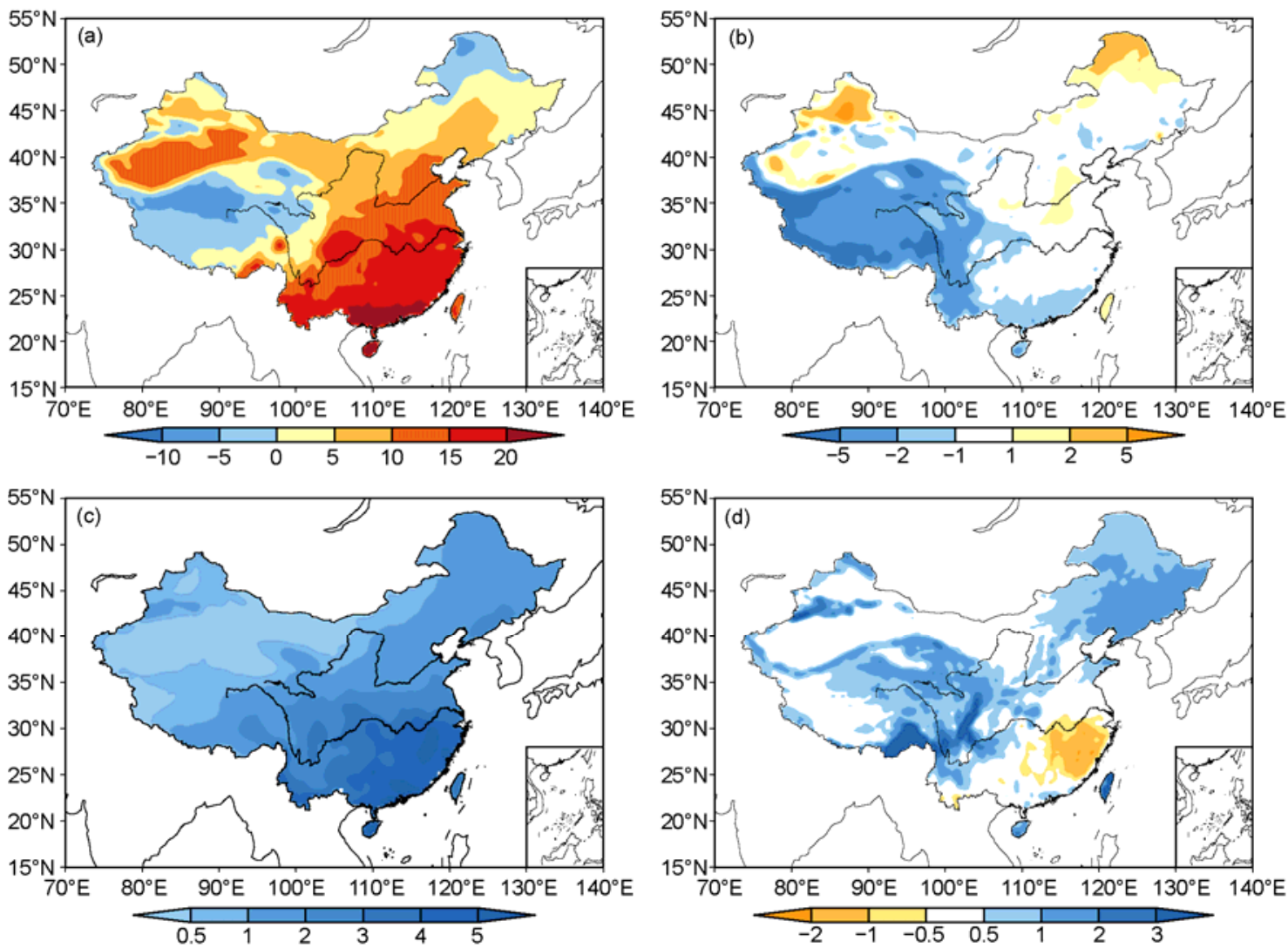

Figure 1 Annual mean temperature $\left({ }^{\circ} \mathrm{C}\right)$ and precipitation $(\mathrm{mm} / \mathrm{d})$ over China. (a) Observed temperature; (b) temperature difference between simulation and observation; (c) observed precipitation; (d) precipitation difference between simulation and observation.

and observation is 0.98 .

Figure 1(c) and (d) compares annual mean precipitation in the simulation with corresponding observations. As shown in Figure 1(c), observedprecipitation maxima arelocated in southeastern China, andit decreases toward the north and northwest withthe minimum found in the basins (also deserts) in the Northwest. The model captures this pattern well although with the discrepancies found mainly as the underestimation in the Southeast and the overt estimation of precipitationin the Northeast. The overestimation of precipitation surrounding the Tibetan Plateau (e.g. Kunlun Mountain and the western part of Sichuan) as well as the mountain peaks in North (Taihang Mountains) and Northwest China (Tianshan and Kunlun Mountains) can be partly attributed to the reason that the model is too sensitive to the topography in the precipitation simulation, while in the meantime, the uncertainties in the observation dataset over the areas (usually underestimate the real precipitation there) also contributes to the discrepancies [40,41]. The spatial correlation coefficient of annual mean temperature between model simulation and observation is 0.81 .

\subsection{Climate extreme indices}

The observed temperature indices of SU, FD and GSL and the differences between the simulation and observation are presented in Figure 2. As shown in the figure, the model in general captures the observed spatial pattern and amount of the 3 indices well. The values of warm events described by GSL and SU show a distribution of high in the south and low in the North, with the lowest exist in the Tibetan Plateau as well as Northeast China, while the cold events described by FD shows a reversed distribution (Figure 2(a), (c),(e)).The model in general reproduces the basic pattern of the spatial distribution although with some discrepancies concerning the amounts. The spatial correlation coefficients of SU, GSL and FD between the simulation and observation are $0.94,0.99$ and 0.99 , respectively.

To be more specific, for GSL, the bias in Hua'nan, North China Plain, Junggar and Tarim basin in Northwest are small or with a minor positive value, but a prevailing negative bias (shorter GSL than the observed) are found over most of the other extended areas. The values of the bias are usually in the range of 10-25 d, except over the Tibetan Plateau where the values can be up in excess of $50 \mathrm{~d}$ corresponding to the cold bias in simulating spring and winter temperature there [23].

For SU, less than the observed values are found in general over the region except the Tibetan Plateau. The largest bias is found in Hua'nan with the values greater than $75 \mathrm{~d}$. 

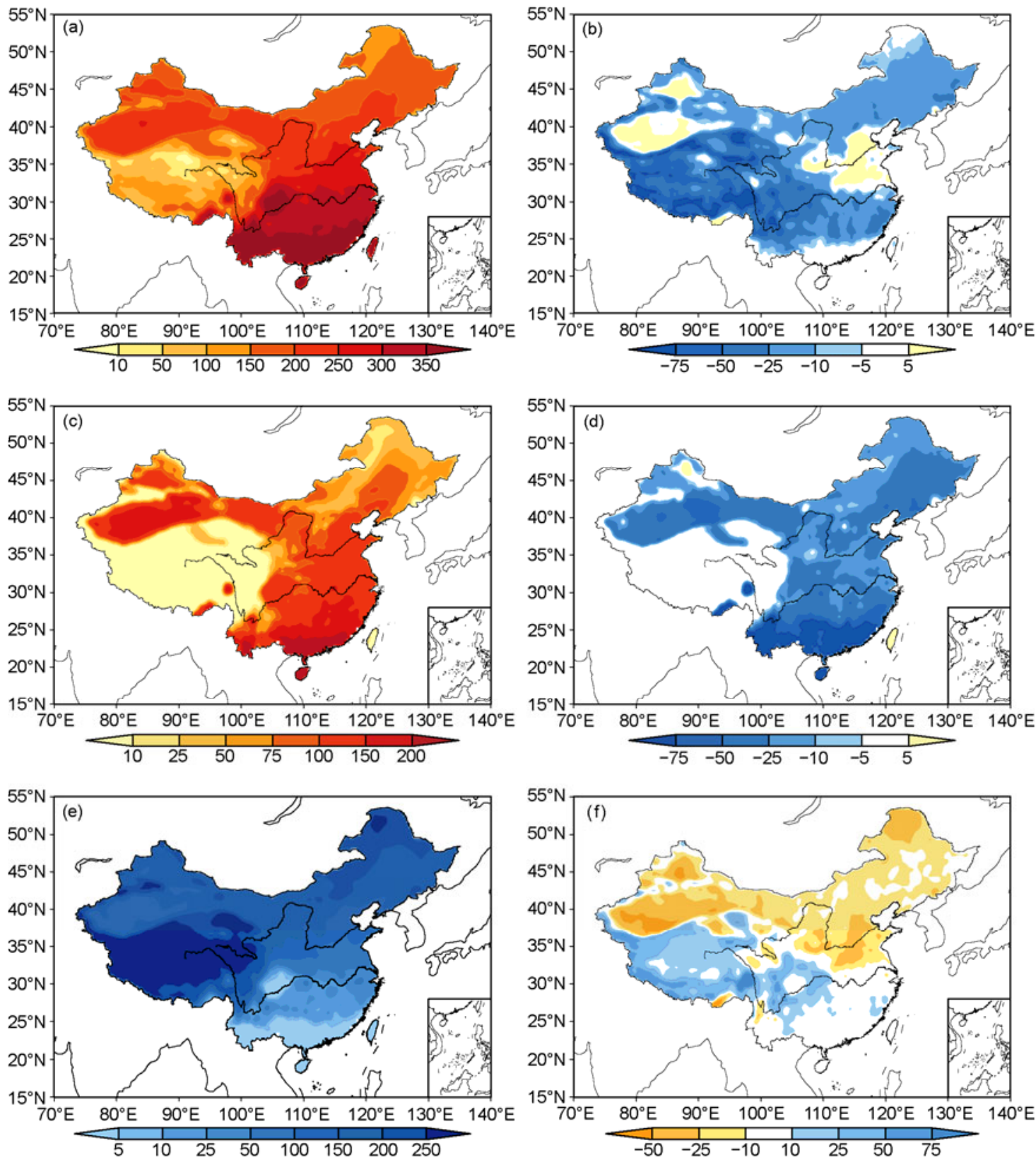

Figure 2 Annual mean SU, FD and GSL over China. (a) Observed GSL; (b) GSL difference between simulation and observation; (c) observed SU; (d) SU difference between simulation and observation; (e) observed FD; (f) FD difference between simulation and observation.

In the meantime, the cold bias in the cold months over the Tibetan Plateau and Sichuan Basin leads to the overestimation of FD in the places with the bias up to $10-50 \mathrm{~d}$ while in northern part of the region, the simulated FD is shorter than that observed with the bias usually in the range of 10-25 d except the even larger values in portions of North and Northeast China, together with the few basins in the Northwest.

The observed precipitation indices of R10, SDII and CDD and the difference between the simulations with the mare presented in Figure 3. The spatial correlation coefficients of the three indices between model simulation and observation are $0.83,0.95$ and 0.84 , respectively. For the index of R10, the spatial pattern (Figure 3(a)) is similar to that of annual mean precipitation (Figure 1(c)) with high value in the southeast and low value in the north and northwest indicating that precipitation amount due to heavy rainfall events occupy a large proportion of the total. Simulated $\mathrm{R} 10$ shows some underestimation in southeastern China and overestimation in the Northeast, east of the Tibetan Plateau and over the mountains, which also agrees with that in the annual mean. The result indicates that the bias in the precipitation simulation may be partly arise from the poorer capability of the model in simulating heavy rainfall events. 

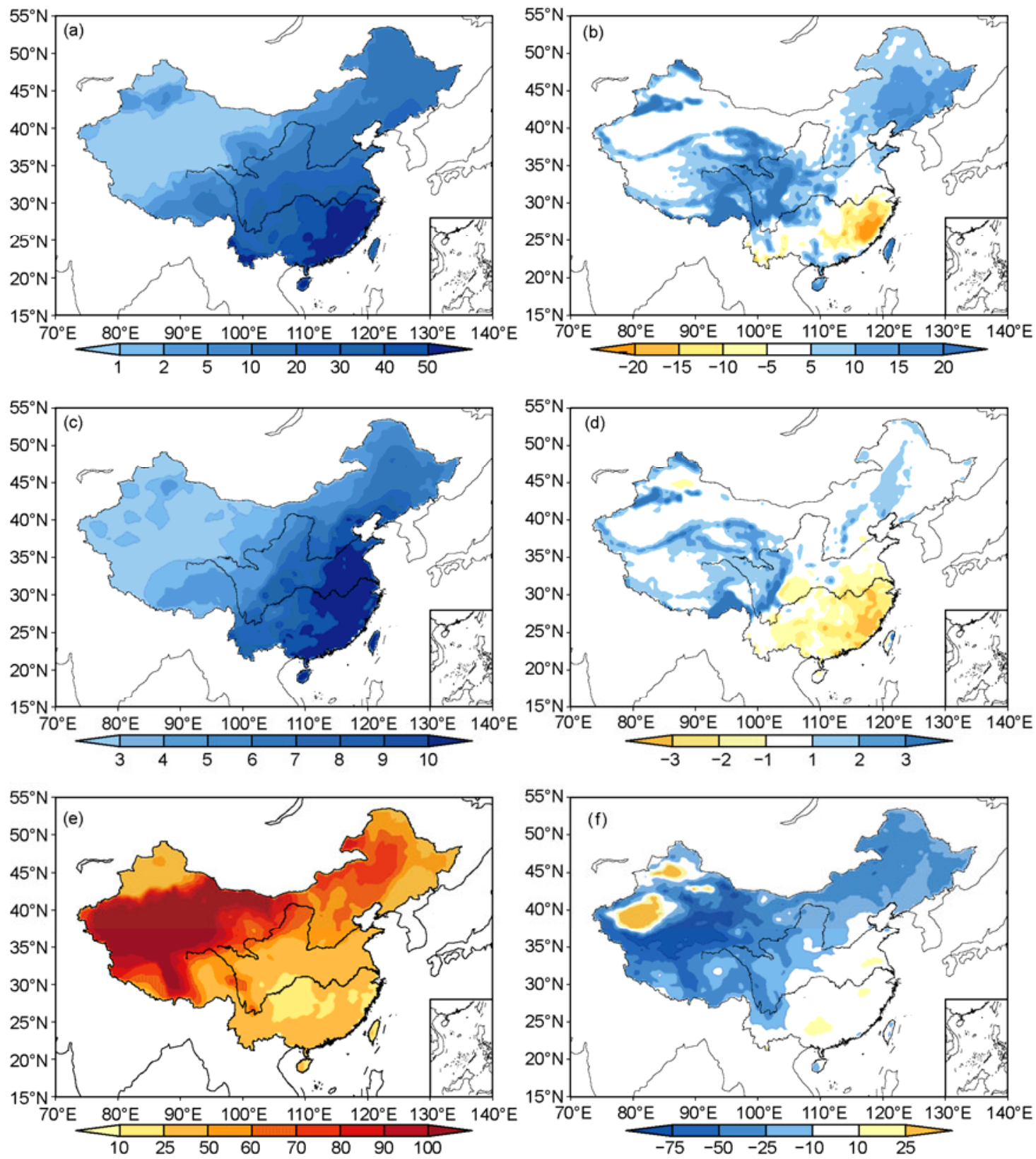

Figure 3 Same as in Figure 2, but for the precipitation indices of R10, SDII and CDD (d \& mm/d).

The distribution of SDII (Figure 3(c)) follows that of R10 but with the maxima further penetrated north to the Huanghuai and Jianghuai areas. The main bias is the underestimation of it along and south of the Yangtze River and overestimation of it over the mountain. The error of RegCM3 in simulating heavy precipitation events can also be found when driven by a different GCM which deserves special attention in the future improvement of the model [16].

In the CDD observation, larger values greater than $60 \mathrm{~d}$ are found in the west part of the Northeast and most places of the Northwest where arid and semiarid climate prevail. Smaller values of less than $50 \mathrm{~d}$ can be found in south of the
Yellow River, with the minimum between 10-25 d exist south of the Yangtze River (Figure 3(e)). The magnitude of the bias varies in the range of $-10-10 \mathrm{~d}$ in eastern China. Over extended areas of the Northeast and western China, the bias is negative and can be up to $50 \mathrm{~d}$.

\section{Changes of climate and climate extremes in the future}

\subsection{Surface air temperature and precipitation}

Changes in annual mean temperature and precipitation are firstly presented in the section to show the background of 
the changes in climate extremes. In the mid-21st century, significant warming compared to the present day can be found over China (Figure 4(a)). The warming is to a less extend $\left(<2.5^{\circ} \mathrm{C}\right)$ south of the Yangtze River, and a greater warming exceeding $3.0^{\circ} \mathrm{C}$ can be found north of the Yellow River and in western China. The maximum warming greater than $3.5^{\circ} \mathrm{C}$ exists in the Northeast and portions of the Tibetan Plateau. As can be found in Figure 4(b), the simulated precipitation changes show a decrease in the Northeast and the Tibetan Plateau, little change within $\pm 5 \%$ in the Southwest and along the Yangtze River basin, whereas increased precipitation can be found in South China and from west of North China extended to the Northwest with the values greater than $25 \%$ located in the basins of Xinjiang and central Inner Mongolia.

\subsection{Climate extreme indices}

Follow the warming, significant increase of GSL is found over China (Figure 5(a)). The increase is lower in Hua'nan and the area along Kunlun Mountain in the Northwest with the value less than $5 \mathrm{~d}$. In the former area, the value of GSL is already high (>350 d, Figure 2(a)) in the present day, while for the latter, it is a cold area with high altitude thus a warming of a few degrees have little effect on the GSL. Less increase with the values in the range of 10-20 d can also be found north of the Northeast and in the basins in Northwest China. The increase over the area from the Yangtze River Basin extended westward to the Tibetan Plateau and its northeast neighboring places can be more than $30 \mathrm{~d}$ with the maxima up to $50 \mathrm{~d}$ exists in the Tibetan Plateau. As shown in Figure 5(b), the regional mean GSL during the 21 st century increases following the time evolution with the values of the increase in the mid- and end (2080-2099) of the 21 st century are 10 and $17 \mathrm{~d}$, respectively.

The change patterns of SU show similar to that of GSL as shown in Figure 5(c), characterized by the general increase over the region, except the Tibetan Plateau and
Tianshan Mountains, as well as other areas with high altitudes. Maximum increase in excess of $50 \mathrm{~d}$ can be found in Hua'nan although the local temperature increase is minimum (Figure 4(a)). This is due to the temperature there is high in the present day while a less warming can have great effect on the calculated SU. Except the middle and lower reaches of the Yellow River and northern of the Northeast, the increase of SU in eastern China is in the range of 30$50 \mathrm{~d}$. In Northwest, less increase can be found with the value between 20 and 30 d. Change of regional mean GSL is also similar with that of SU in the 21 st century, the values in the mid and end of the 21 st century is 8 and $13 \mathrm{~d}$, respectively (Figure 5(d)).

Widespread decrease of FD is observed in Figure 5(e) due to the warming. Except Hua'nan and Kunlun Mountain, the decrease in Sichuan Basin is also small $(<5 \mathrm{~d})$. Large decrease can be found from the lower reaches of the Yellow River extended to the Tibetan Plateau, with the value in a range of 30-50 d. Regional mean FD shows a significant trend of decrease (Figure 5(f)), the value in the mid- and end of the 21st century is 9 and $15 \mathrm{~d}$, respectively.

Similar to temperature, changes of the precipitation indices of R10, SDII and CDD in the future, including spatial pattern in the mid-21st century and the time series in the 21 st century are presented in Figure 6. As can be found in Figure 6(a), the spatial pattern of R10 changes in the mid21 st century agrees with that of annual mean precipitation (Figure 4(b)), indicating the large portions of the extreme precipitation take in the total amount. The heavy rainfall as measured by R10 increase in the areas where precipitation increase, and vice versa. Greater increase can be found in the Northwest with the value greater than $25 \%$, and can be in excess of $50 \%$ over portions of the area. For the regional mean changes, R10 shows a general trend of increase in the 21 st century, but not so uniform with that of the temperature indices. A kind of decadal variation, for example the relative low value around 2070 can be found. The values in the mid and end of the 21 st century are $5 \%$ and $10 \%$, respectively.
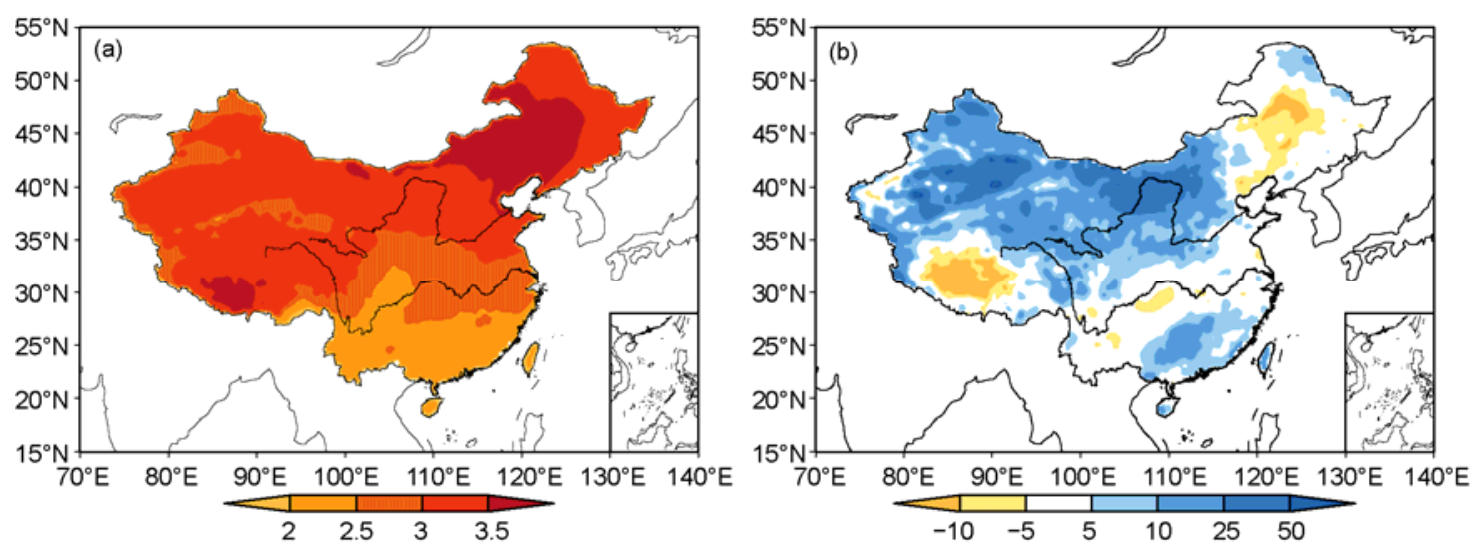

Figure 4 Changes of temperature $\left({ }^{\circ} \mathrm{C}\right)$ and precipitation (\%) over China in the mid-21st century (in relative to 1980-1999). (a) Temperature; (b) precipitation. 

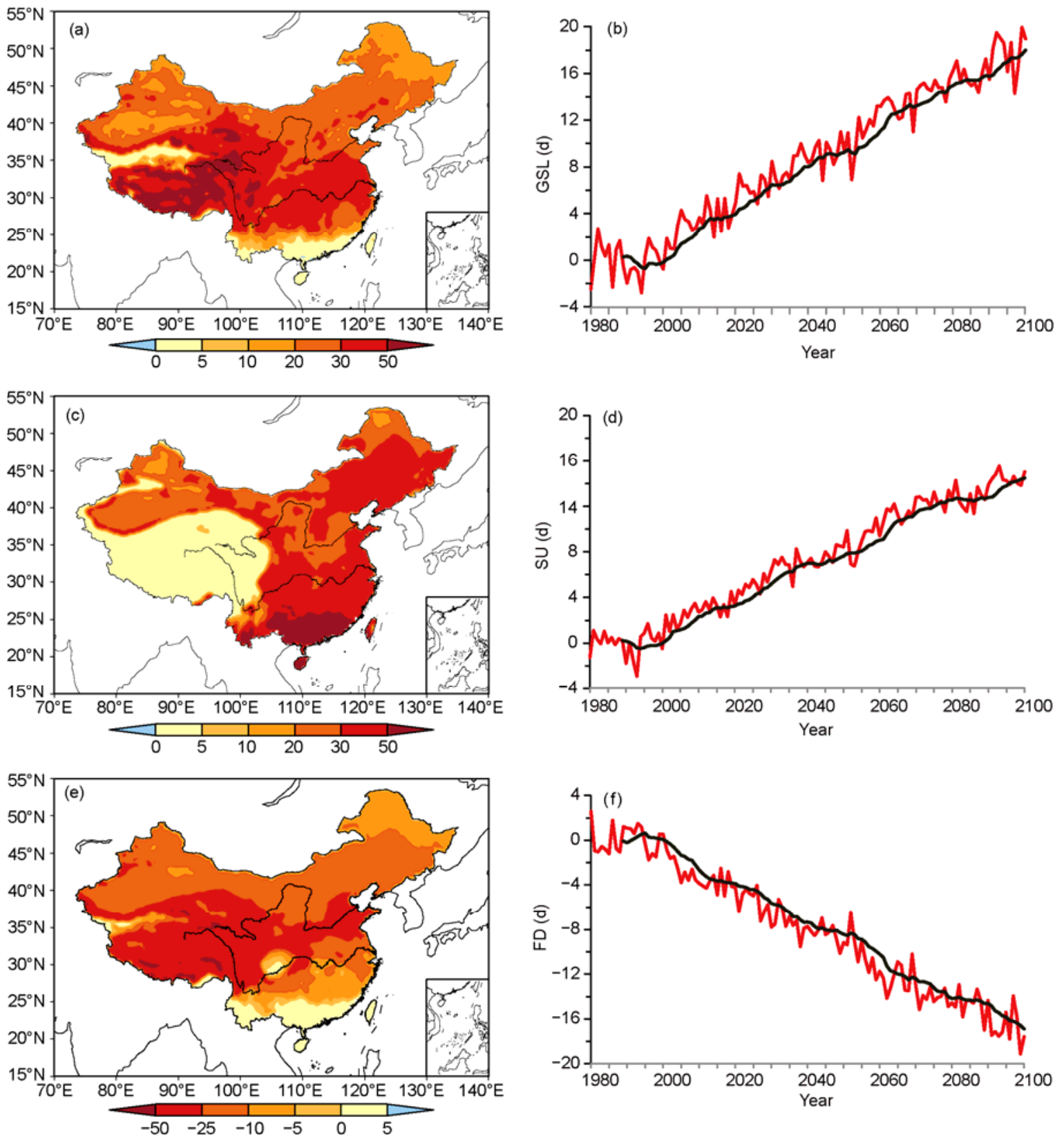

Figure 5 Changes of SU, FD and GSL over China in the mid-21st century (in relative to 1980-1999). (a) GSL, mid-21st century; (b) GSL, regional mean in 21st century; (c) SU, mid-21st century; (d) SU, regional mean in 21st century; (e) FD, mid-21st century; (f) FD, regional mean in 21st century. The black lines in the right panels are 10 -year moving average.

Different from the decrease of R10 in the Northeast and the Tibetan Plateau, less change or a small decrease of the intensity index of precipitation (SDII) over the areas while a general increase elsewhere over the country can be found (Figure 6(c)). The increase can be up to $10 \%-25 \%$ in the areas distributed in South China, Inner-Mongolia, Tibetan Plateau and Northwest China. Regional mean SDII shows a more linear increase compared to that of R10 (Figure 6(d)) while the values in the middle and end of the 21 st century are $5 \%$ and $12 \%$, respectively.

Change of CDD shows a negative-positive dipole change over the region with a decrease of $10 \%-25 \%$ in the north and an increase can be larger than $25 \%$ in the Tibetan Plateau, middle reaches of the Yangtze River and Hua'nan (Figure 6(e)). This north-south oriented pattern will lead to less drought events in the north, and more droughts in the south. In general, only minor changes in the regional mean CDD can be found in the 21st century (Figure 6(f)).

\section{Conclusions and discussions}

A 150-year's transient climate change simulation, from 1951-2100, was conducted over East Asia using the regional 

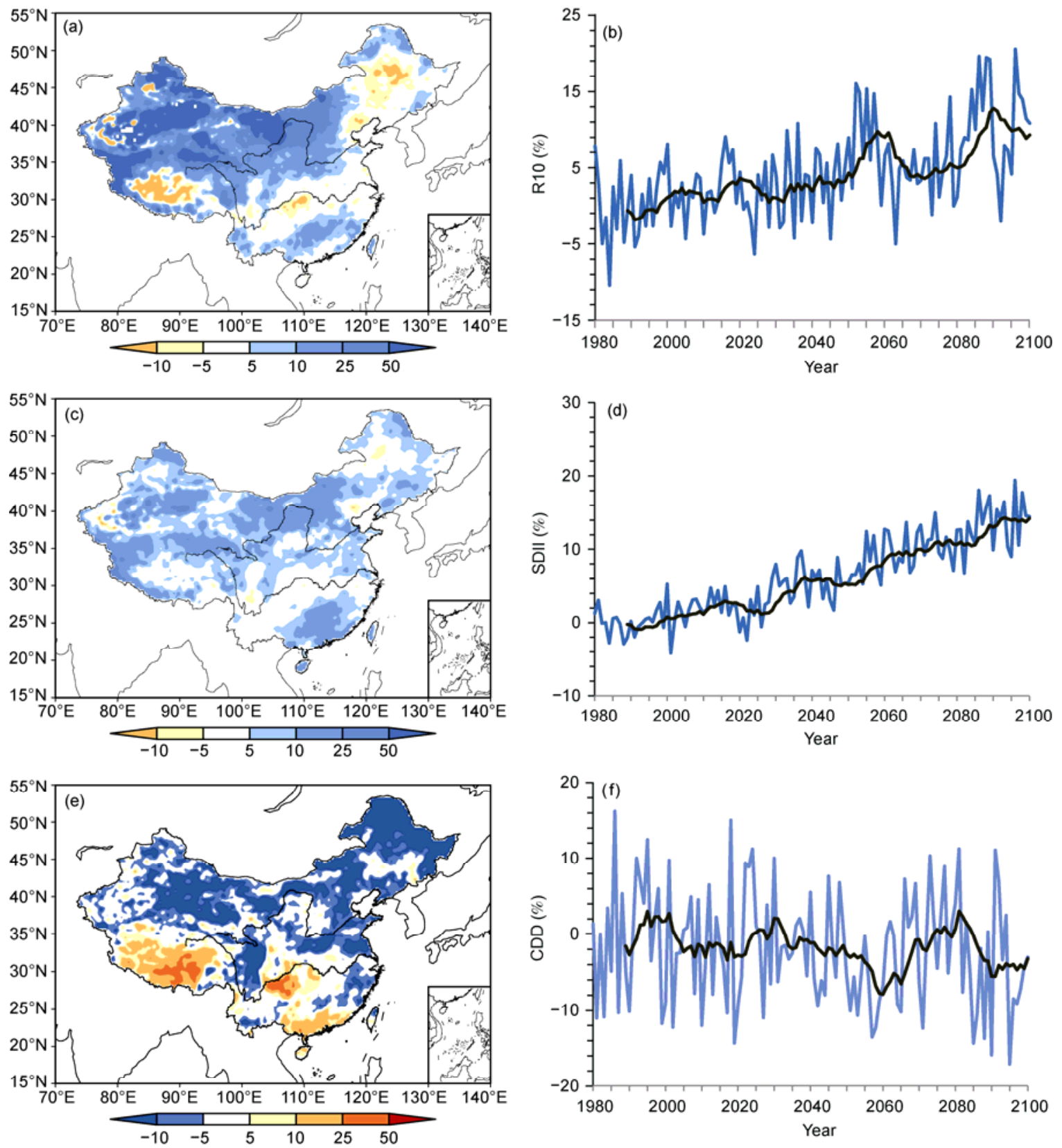

Figure 6 Same as in Figure 5, but for precipitation indices of R10, SDII and CDD (\%).

climate model RegCM3 at $25 \mathrm{~km}$ grid spacing. The model was driven by the global model of MIROC3.2_hires under the IPCC SRES A1B scenario. We first evaluate the performance of the RegCM3 in simulating the indices of temperature and precipitation by comparing the simulation against observations. In general, RegCM3 can reasonably reproduce the spatial pattern and value of climate extreme indices well. Discrepancies can also be found, e.g. the underestimation of GSL and SU over many areas while the values of FD show less in the north and more in the Tibetan Plateau as compared with that observed. In the meantime, the model capability in simulating heavy rainfall events should be further improved.
Based on the validation of the model above, we then analyze the simulated future changes of climate extreme indices over China. Our main findings include:

(1) Substantial warming in annual mean temperature is simulated over China. The warming shows a latitudinal distribution with less in the south and greater in the north. The largest warming can be found in the Northeast and the Tibetan Plateau. Annual mean precipitation shows a significant decrease in the central part of the Northeast and Tibetan Plateau, less change in the mid and lower reaches of the Yangtze River, and general increase elsewhere.

(2) Broad increase of SU and GSL, decrease of FD are found as expected over the region under the warming, ex- 
cept the little change of SU over the Tibetan Plateau. The maximum increase of GSL and decrease of FD in the Tibetan Plateau, while that of SU in Hua'nan are simulated by the model. The change of increase or decrease of the indices becomes more significant following time evolution in the 21 st century. The increase of FD in summer in the future can exert impacts on human society and economic life, while the prolonged GSL and shortened FD plus the precipitation change will have great effect on the agriculture production and ecological environment. But further studies on the impacts of the changes in the extremes are indeed needed in the future.

(3) Change of R10 follows that of precipitation. Increase of SDII found in many places indicate the increased precipitation intensity in the warmer conditions with an enhanced hydrological cycle processes, and may lead to more flood. As a drought indicator, pronounced increase of CDD is found in southern China, including south of Sichuan Basin. Although little change of CDD can be found in Yunnan, considering the increased evaporation due to the warming, the events like the successive drought disasters found in the late years over the are a may happen frequently in the future [42]. The decrease of CDD in the North, Northeast and Northwest China may be favorable to the local society and ecosystems. However, further investigations are needed to understand whether this decrease may compensate the greater evapotranspiration in the warming climate or not. It is noted that the changes of R10 and SDII are in the same direction as that of CDD in Hua'nan and Northeast China, indicating the increase of both flood and drought events in the areas in the future.

(4) Large uncertainties exist in the simulation and projection of future climate changes, which arise from emission scenarios of GHGs, limitations in current capabilities of climate models, availability of high resolution observation data to validate the models, and the overall further in-depth knowledge needed of the global climate system. The uncertainties also can be found in simulation and projection of climate extremes. Multi-model ensembles of climate projections are important pathways for reducing these uncertainties. We plan to conduct transient simulations with different driving GCMs and scenarios to obtain more reliable information on climate change in China. Our final goal is to provide more scientifically robust and valuable suggestions for the assessment of impacts and the implementation of adaptation measures.

This work was supported by the National Basic Research Program of China (2009CB421407), Major Science and Technology Projects in Zhejiang Province (2009C03008-2) and the National Natural Science Foundation of China (40975041).

1 Diffenbaugh N S, Pal J S, Giorgi F, et al. Heat stress intensification in the Mediterranean climate change hotspot. Geophys Res Lett, 2007, 34: L11706

2 Emori S, Hasegawa A, Suzuki T, et al. Validation, parameterization dependence, and future projection of daily precipitation simulated with a high-resolution atmospheric GCM. Geophys Res Lett, 2005, 32: L06708

3 Gao X J, Pal J S, Giorgi F. Projected changes in mean and extreme precipitation over the Mediterranean region from a high resolution double nested RCM simulation. Geophys Res Lett, 2006, 33: L03706

4 Mearns L O, Hulme M, Carter T R, et al. Climate Scenario Development. In: Climate Change 2001: The Scientific Basis, Contribution of Working Group I to the Third Assessment Report of the IPCC. Cambridge: Cambridge University Press, 2001. 583-638

5 Tebaldi C, Hayhoe K, Arblaster J M, et al. Going to the extremes, An inter-comparison of model-simulated historical and future changes in extreme events. Clim Change, 2006, 79: 185-211

6 Torma C, Coppola E, Giorgi F, et al. Validation of a high-resolution version of the regional climate model RegCM3 over the Carpathian Basin. J Hydro Meteorol, 2011, 12: 84-100

7 Zhai P M, Pan X H. Trends in temperature extremes during 19511999 in China. Geophys Res Lett, 2003, 30: 1913-1916

8 Zhai P M, Zou X K. Changes in temperature and precipitation and their impacts on drought in China during 1951-2003 (in Chinese). Adv Clim Changes Res, 2005, 1: 16-18

9 Qian W H, Lin X. Regional trends in recent precipitation indices in China. Meteorol Atmos Phys, 2005, 90: 193-207

10 Feng J M, Wang Y G, Fu C B. Simulation of extreme climate events over China with different regional climate models. Atmos Ocean Sci Lett, 2011, 4: 47-56

11 Gao X J, Zhao Z C, Giorgi F. Changes of extreme events in regional climate simulations over East Asia. Adv Atmos Sci, 2002, 19: 927942

12 Gao X J, Shi Y, Giogi F. A high resolution simulation of climate change over China. Sci China Earth Sci, 2011, 54: 462-472

13 Shi Y, Gao X J, Giorgi F, et al. High resolution simulation of changes in extreme precipitation events over China under global warming (in Chinese). Adv Clim Changes Res, 2010, 6: 164-169

14 Sun J Q, Wang H J, Yuan W, et al. Spatial-temporal features of intense snowfall events in China and their possible change. J Geophys Res, 2010, 115: D16110

$15 \mathrm{Xu} \mathrm{Y,} \mathrm{Xu} \mathrm{C} \mathrm{H,} \mathrm{Gao} \mathrm{X} \mathrm{J,} \mathrm{et} \mathrm{al.} \mathrm{Projected} \mathrm{changes} \mathrm{in} \mathrm{temperature} \mathrm{and}$ precipitation extremes over the Yangtze River Basin of China in the 21st century. Quat Int, 2009, 208: 44-52

16 Zhai P M, Zhang X B, Wan H, et al. Trends in total precipitation and frequency of daily precipitation extremes over China. J Clim, 2005, 18: 1096-1108

17 Zhang Y, Xu Y L, Dong W J, et al. A future climate scenario of regional changes in extreme climate events over China using the PRECIS climate model. Geophys Res Lett, 2006, 33: L24702

18 Chen H P, Sun J Q, Fan K. Decadal features of heavy rainfall events in eastern China. Acta Meteorol Sin, 2012, 26: 289-303

19 Wang S, Yu E, Wang H. A simulation study of a heavy rainfall process over the Yangtze River valley using the two-way nesting approach. Adv Atmos Sci, 2012, 29: 731-743

20 Wang H J, Sun J Q, Chen H P, et al. Extreme climate in China: Facts, simulation and projection. Meteorol Z, 2012, 21: 279-304

21 Gao X J, Xu Y, Zhao Z C, et al. On the role of resolution and topography in the simulation of East Asia precipitation. Theor Appl Climatol, 2006, 86: 173-185

22 Gao X J. Researches in projection of extreme events in China (in Chinese). Adv Clim Changes Res, 2007, 3: 162-166

23 Gao X J, Shi Y, Zhang D F, et al. Climate change in China in the 21st century as simulated by a high resolution regional climate model (RegCM3). Chin Sci Bull, 2012, 57: 1188-1195

24 Gao X J, Shi Y, Zhang D F, et al. Uncertainties in monsoon precipitation projections over China: Results from two high-resolution RCM simulations. Clim Res, 2012, 52: 213-226

25 Giorgi F, Marinucci M R, Bates G T. Development of a second- generation regional climate model (RegCM2). Part I: Boundary-layer and radiative transfer processes. Mon Weather Rev, 1993, 121: 27942813

26 Giorgi F, Marinucci M R, Bates G T, et al. Development of a sec- 
ond-generation regional climate model (RegCM2). Part II: Convective processes and assimilation of lateral boundary conditions. Mon Weather Rev, 1993, 121: 2814-2832

27 Pal J S, Giorgi F, Bi X Q, et al. Regional climate modeling for the developing world: The ICTP RegCM3 and RegCNET. Bull Amer Meteorol Soc, 2007, 88: 1395-1409

28 K-1 Model Developers. K-1 coupled model (MIROC) description. In: Hasumi H, Emori S, eds. K-1 Technical Report 1. Tokyo: University of Tokyo, 2004

29 IPCC. Special Report on Emissions Scenarios, A Special Report of WGIII of the IPCC. In: Nakicenovic N, Alcamo J, Davis G, et al., eds. Cambridge: Cambridge University Press, 2000. 599

30 Kiehl J, Hack J, Bonan G, et al. Description of the NCAR Community Climate Model (CCM3). NCAR Technical Note, NCAR/TN-420 STR. 1996

31 Holtslag A, de Bruijin E, Pan H L. A high resolution air mass transformation model for short-range weather forecasting. Mon Weather Rev, 1990, 118: 1561-1575

32 Pal J S, Small E E, Eltahir E. Simulation of regional-scale water and energy budgets: Representation of subgrid cloud and precipitation processes within RegCM. J Geophys Res, 2000, 105: 29579-29594

33 Grell G. Prognostic evaluation of assumptions used by cumulus parameterizations. Mon Weather Rev, 1993, 121: 764-787

34 Fritsch J M, Chappell C F. Numerical prediction of convectively driven mesoscale pressure systems. Part I. Convective parameteriza- tion. J Atmos Sci, 1980, 37: 1722-1733

35 Dickinson R E, Kennedy P J, Henderson-Sellers A, et al. Biosphereatmosphere transfer scheme (bats) for the NCAR community climate model. NCAR Technical Report, 1986

36 Zeng X, Zhao M, Dickinson R E. Intercomparison of bulk aerodynamic algoriths for the computation of sea surface fluxes using TOGACOARE and TAO data. J Clim, 1998, 11: 2628-2644

37 Wu J, Gao X J. A gridded daily observation dataset over Chinaregion and comparison with the other datasets (in Chinese). Chin J Geophys, 2013, 56, doi: 10.6038/cjg20130301

38 Frich P, Alexander L V, Della-Marta P, et al. Observed coherent changes in climatic extremes during the second half of the twentieth century. Clim Res, 2002, 19: 193-212

39 Zhang D F, Gao X J, Ouyang L C, et al. Simulation of present climate over East Asia by a regional climate model. J Trop Meteor, 2008, 14: 19-23

40 Shi Y, Gao X J, Wu J, et al. Simulating future climate change over North China with a high resolution regional climate model (in Chinese). J Appl Meteorol Sci, 2010, 21: 580-589

$41 \mathrm{Wu}$ J, Gao X J, Shi Y, et al. Climate change over Xinjiang region in the 21 st century simulated by a high resolution regional climate model (in Chinese). J Glaciol Geocryol, 2011, 33: 479-487

42 Huang R H, LiuY, Wang L, et al. Analyses of the causes of severe drought occurring in Southwest China from the fall of 2009 to the spring of 2010 (in Chinese). Chin J Atmos Sci, 2012, 36: 443-457

Open Access This article is distributed under the terms of the Creative Commons Attribution License which permits any use, distribution, and reproduction in any medium, provided the original author(s) and source are credited. 